\title{
Review: Water medication of growing pigs: sources of between- animal variability in systemic exposure to antimicrobials
}

\author{
S. B. Little ${ }^{1 \dagger} \oplus$, H. K. Crabb' ${ }^{1}$ A. P. Woodward², G. F. Browning ${ }^{1}$ and H. Billman-Jacobe ${ }^{1}$ \\ ${ }^{1}$ Asia Pacific Centre for Animal Health, Faculty of Veterinary and Agricultural Sciences, and National Centre for Antimicrobial Stewardship, University of Melbourne, \\ Parkville, Victoria 3010, Australia; ${ }^{2}$ Faculty of Veterinary and Agricultural Sciences, University of Melbourne, Parkville, Victoria 3010, Australia
}

(Received 24 May 2019; Accepted 19 July 2019; First published online 2 September 2019)

On many Australian commercial pig farms, groups of growing pigs are mass-medicated through their drinking water with selected antimicrobials for short periods to manage herd health. However, delivery of medication in drinking water cannot be assumed to deliver an equal dose to all animals in a group. There is substantial between-animal variability in systemic exposure to an antimicrobial (i.e. the antimicrobial concentration in plasma), resulting in under-dosing or over-dosing of many pigs. Three sources of this between-animal variability during a water medication dosing event are differences in: (1) concentration of the active constituent of the antimicrobial product in water available to pigs at drinking appliances in each pen over time, (2) medicated water consumption patterns of pigs in each pen over time, and (3) pharmacokinetics (i.e. oral bioavailability, volume of distribution and clearance between pigs and within pigs over time). It is essential that factors operating on each farm that influence the range of systemic exposures of pigs to an antimicrobial are factored into antimicrobial administration regimens to reduce under-dosing and over-dosing.

Keywords: antimicrobial concentration, water consumption, pharmacokinetics, efficacy, antimicrobial resistance

\section{Implications}

Antimicrobials provide substantial animal productivity, health and welfare benefits to the Australian pig industry. Mass medication of groups of growing pigs through drinking water offers several advantages over continuous antimicrobial administration in feed, and is a valuable tool for pig producers and veterinarians. However, significant variation between pigs in systemic exposure to an antimicrobial (i.e. the antibiotic concentration in plasma over time) occurs when a group of pigs is administered an antimicrobial through their drinking water. Many pigs in a group may be under-dosed or over-dosed. Under-dosing with an antimicrobial may lead to reduced clinical efficacy and failure to eliminate the target pathogen, and thus may contribute to the development of antimicrobial resistance in pig-specific bacterial pathogens. Over-dosing may increase the risk of toxicity to the animal and the persistence of residues in pigs at slaughter, and unnecessarily increase farm medication costs.

\section{Introduction}

On many commercial pig farms, groups of growing pigs are mass-medicated for short periods with antimicrobials

\footnotetext{
${ }^{\dagger}$ E-mail: littles2@student.unimelb.edu.au
}

through their drinking water to manage herd health. This method of delivery, commonly called 'water medication', may be conducted strategically at regular intervals to achieve metaphylaxis and when necessary to treat clinical disease caused by bacterial pathogens.

A water medication dosing event on a pig farm commonly involves administration of the calculated dose of a selected antimicrobial product to a group of pigs over several hours. On Australian pig farms, dosing events are typically commenced after sunrise, when pigs have begun eating and drinking and regular farm staff members have commenced their working day. A dosing event may be conducted once or repeated on several consecutive days.

Two methods are used on commercial pig farms to massmedicate pigs through their drinking water: (1) Direct dosing of the water supply by adding medication into a header tank located at or within each shed, or (2) proportional dosing, using a water or electric-powered pump that continuously draws up a concentrated stock solution of medication from a container and injects it into a shed's drinking water supply line at a volumetric ratio that can be set by the operator. A recent survey of Australian pig farms found that the majority had water medication dosing systems. Most farmers used proportional dosing pumps to deliver medications into the drinking water line, while some used direct dosing (Edwards, 2018). 


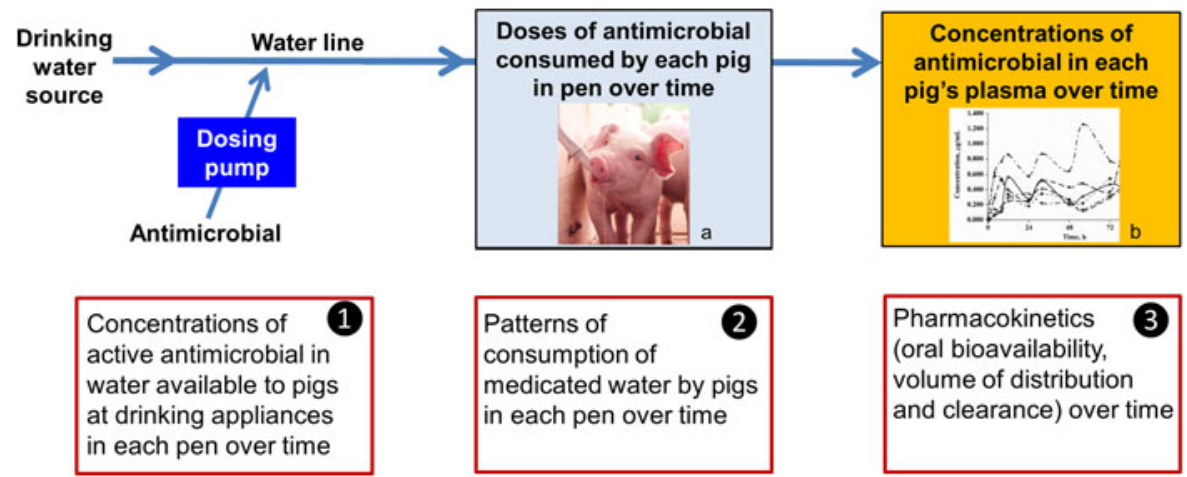

Figure 1 (Colour online) Sources of variability in systemic exposure of pigs to an antimicrobial during a water medication dosing event. a Source: Kanters Special Products BV.

b Source: Mason et al. (2009).

When a regimen for antimicrobial administration through drinking water or feed ad libitum for a group of pigs is determined, the dose is commonly based on a measurement or estimate of the average BW of the group and the pigs' daily water or feed consumption. However, it cannot be assumed that all animals will experience the same level of systemic exposure to the antimicrobial over time. Several studies have assessed the pharmacokinetic (PK) parameters of different water-soluble antimicrobials after administration to pigs in drinking water offered ad libitum over several days. These studies found significant variation between pigs in systemic exposure to the antimicrobial and time taken from commencement of administration to attainment of a steady-state plasma concentration of antimicrobial.

Prats et al. (2005) found that when 20 to $25 \mathrm{~kg}$ pigs penned in groups of six were administered doxycycline in water offered ad libitum for 5 days, the mean maximum plasma concentration $\left(C_{\text {max }}\right)$ was $2.2 \mu \mathrm{g} / \mathrm{ml}$ (SD: $\left.1.6 \mu \mathrm{g} / \mathrm{ml}\right)$, and the mean area under the plasma antimicrobial concentration-time curve (AUC) was $138.4 \mu \mathrm{g} \cdot \mathrm{h} / \mathrm{ml}$ (SD: $125.5 \mu \mathrm{g} \cdot \mathrm{h} / \mathrm{ml})$. Jensen et al. (2006) administered amoxicillin to individually penned weanling pigs in water offered ad libitum for $4 \mathrm{~h} /$ day (after withholding water for $3 \mathrm{~h}$ ) for 2 days. They found large variations between pigs' $C_{\max }$ and AUC values. This was associated with large variation in the dose of amoxicillin consumed (control pigs, Day 1: median dose ingested: $26 \mathrm{mg} / \mathrm{kg}$ (range: 9 to $41 \mathrm{mg} / \mathrm{kg}$ ); median $C_{\max } /$ dose: $0.29 \mathrm{~kg} /$ (range: 0.14 to $1.03 \mathrm{~kg} / \mathrm{l}$ ); median AUC/dose: $2.5 \mathrm{~kg} \cdot \mathrm{h} / \mathrm{l}$ (range: 1.3 to $5.9 \mathrm{~kg} \cdot \mathrm{h} / \mathrm{l})$ ). Mason et al. (2009) administered tetracycline to individually penned $16 \mathrm{~kg}$ pigs at three concentrations $(125,250$ and $500 \mathrm{mg} / \mathrm{l})$ in water offered ad libitum for 5 days. The mean $A U C_{\text {total }}$ values found were $30.71 \mu \mathrm{g} \cdot \mathrm{h} / \mathrm{ml}$ (SD: $6.61 \mu \mathrm{g} \cdot \mathrm{h} / \mathrm{ml}$ ), $44.93 \mu \mathrm{g} \cdot \mathrm{h} / \mathrm{ml}$ (SD: $8.26 \mu \mathrm{g} \cdot \mathrm{h} / \mathrm{ml}$ ) and $73.74 \mu \mathrm{g} \cdot \mathrm{h} / \mathrm{ml}$ (SD: $4.88 \mu \mathrm{g} \cdot \mathrm{h} / \mathrm{ml}$ ) respectively. Lindquist et al. (2014) found that when weanling pigs penned in groups of 10 were administered tetracycline in water offered ad libitum for 5 days, their mean plasma tetracycline concentration at $102 \mathrm{~h}$ was $1309 \mathrm{mg} / \mathrm{l}$ (SD: $492 \mathrm{mg} / \mathrm{l})$.

Several studies have also detected high levels of betweenanimal variability in plasma concentrations when an antimicrobial was administered to pigs through feed ad libitum over several days (Agersø and Friis, 1998a; Anfossi et al., 2002; del
Castillo et al., 2006; Reyns et al., 2007; Godoy et al., 2011; Soraci et al., 2014). Soraci et al. found that between-animal variability in plasma concentrations was higher when fosfomycin was administered to pigs through feed ad libitum than through drinking water ad libitum, with CVs of $41 \%$ to $61 \%$ for feed compared to $19 \%$ to $30 \%$ for water. If these estimates of variability are accurate, then water medication has an important advantage over in-feed medication.

Understanding the sources of between-animal variability in systemic exposure to an antimicrobial when medicating a group of pigs on a farm through their drinking water is critical. It enables dosage regimens to be designed which not only are effective but also minimise development of antimicrobial resistance (Toutain and Lees, 2006; Bon et al., 2018). These are as follows:

1. Variability in dose applied; that is, the concentration of the active constituent of the antimicrobial product in water available to pigs at drinking appliances in each pen over time,

2. Variability in dose consumed; that is, patterns of consumption of medicated water by pigs in each pen over time, and

3. Variability in PKs; that is, oral bioavailability, volume of distribution and clearance between pigs and within pigs over time (Figure 1).

In this review, we explore these three sources of variability, identifying knowledge gaps, and consider the implications for successfully water medicating pigs at the group level.

\section{Variability in the concentration of active antimicrobial in water over time}

\section{Antimicrobial product solubility}

Solubility is the most critical factor in the formulation of any antimicrobial product that is administered to pigs through drinking water. After mixing in water, the active constituent must remain in solution at close to the concentration required for clinical efficacy and maximum inhibitory activity against the targeted microbe for the entire dosing period. Solubility contributes not only to the dose of the active constituent consumed by the pig, but also to its absorption and distribution in the animal (Crea et al., 2012).

Table 1 provides details about nine water-soluble antimicrobial products registered in Australia that are commonly 
Table 1 Nine water-soluble antimicrobial products registered in Australia that are commonly administered to pigs

\begin{tabular}{|c|c|c|c|c|c|}
\hline Product & Active constituent(s) & $\begin{array}{l}\text { Strength } \\
\text { (proportion of active } \\
\text { constituent in product) }\end{array}$ & $\begin{array}{l}\text { Solubility of active } \\
\text { constituent in } \\
\text { water }^{\text {b }}(\mathrm{mg} / \mathrm{ml})\end{array}$ & $\begin{array}{l}\text { Concentration of active } \\
\text { constituent(s) in water at pigs' } \\
\text { drinking appliance as per label } \\
\text { directions (mg/ml) }\end{array}$ & $\begin{array}{l}\text { Antibiotic : water ratio by } \\
\text { volume for dosing pump } \\
\text { above which solubility } \\
\text { of active constituent } \\
\text { (based on } a \text { and b) is exceedec }\end{array}$ \\
\hline$A$ & Amoxycillin as amoxycillin trihydrate & $870 \mathrm{~g}$ amoxycillin/kg & $2.7^{\mathrm{a}} \mathrm{mg}$ amoxycillin trihydrate/ml & $\begin{array}{l}0.2 \mathrm{mg} / \mathrm{ml} \\
(=0.23 \mathrm{mg} \text { product } / \mathrm{ml} \times 0.87)\end{array}$ & $1: 14$ \\
\hline B & $\begin{array}{l}\text { Lincomycin as lincomycin } \\
\text { hydrochloride }\end{array}$ & $>790 \mathrm{~g}$ lincomycin $/ \mathrm{kg}$ & $50^{\mathrm{a}} \mathrm{mg}$ lincomycin hydrochloride/ml & $\begin{array}{l}0.032 \mathrm{mg} / \mathrm{ml} \\
(=0.041 \mathrm{mg} \text { product } / \mathrm{ml} \times 0.79)\end{array}$ & $1: 1562$ \\
\hline C & Trimethoprim-sulphadiazine & $\begin{array}{l}80 \mathrm{~g} \text { trimethoprim/ } / \mathrm{kg} \text { and } \\
400 \mathrm{~g} \text { sulphadiazine } / \mathrm{kg}\end{array}$ & $\begin{array}{l}4.0^{\mathrm{b}} \mathrm{mg} \text { trimethoprim } / \mathrm{ml} \text { and } \\
6.7^{\mathrm{b}} \mathrm{mg} \text { sulphadiazine } / \mathrm{ml}\end{array}$ & $\begin{array}{l}0.053 \mathrm{mg} \text { trimethoprim } / \mathrm{ml} \\
(=0.667 \mathrm{mg} \text { product } / \mathrm{ml} \times 0.08) \\
\text { and } 0.267 \mathrm{mg} \text { sulphadiazine } / \mathrm{ml} \\
(=0.667 \times 0.4)\end{array}$ & $\begin{array}{r}1: 25 \text { (sulphadiazine being } \\
\text { the more limiting active) }\end{array}$ \\
\hline D & $\begin{array}{l}\text { Oxytetracycline as oxytetracycline } \\
\text { hydrochloride }\end{array}$ & $880 \mathrm{~g}$ oxytetracycline/kg & $\begin{array}{l}>100^{\mathrm{a}} \mathrm{mg} \text { oxytetracycline } \\
\text { hydrochloride/ml }\end{array}$ & $\begin{array}{l}0.293 \mathrm{mg} / \mathrm{ml} \\
(=0.333 \mathrm{mg} \mathrm{product} / \mathrm{ml} \times 0.88)\end{array}$ & $1: 341$ \\
\hline $\mathrm{E}$ & $\begin{array}{l}\text { Chlortetracycline as chlortetracycline } \\
\text { hydrochloride }\end{array}$ & $\begin{array}{l}950 \mathrm{~g} \text { chlortetracycline } \\
\text { hydrochloride/kg }\end{array}$ & $\begin{array}{l}\text { 8.6 } 6^{\mathrm{a}} \mathrm{mg} \text { chlortetracycline } \\
\text { hydrochloride/ml }\end{array}$ & $\begin{array}{l}0.238 \mathrm{mg} / \mathrm{ml} \\
(=0.25 \mathrm{mg} \mathrm{product} / \mathrm{ml} \times 0.95)\end{array}$ & $1: 36$ \\
\hline $\mathrm{F}$ & $\begin{array}{l}\text { Lincomycin as lincomycin } \\
\text { monohydrate } \\
\text { Spectinomycin as the } \\
\text { sulphate tetrahydrate }\end{array}$ & $\begin{array}{l}222 \mathrm{~g} \text { lincomycin } / \mathrm{kg} \text { and } \\
445 \mathrm{~g} \text { spectinomycin/ } \\
\mathrm{kg}\end{array}$ & $\begin{array}{l}50^{\mathrm{a}} \mathrm{mg} \text { lincomycin hydrochloride/ml } \\
\text { and 50a mg Spectinomycin } \\
\text { pentahydrate/ml }\end{array}$ & $\begin{array}{l}0.02 \mathrm{mg} \mathrm{lincomycin} / \mathrm{ml} \\
(=0.094 \mathrm{mg} \mathrm{product} / \mathrm{ml} \times 0.222) \\
\text { and } 0.04 \mathrm{mg} \mathrm{spectinomycin} / \mathrm{ml} \\
(=0.094 \mathrm{mg} \mathrm{product} / \mathrm{ml} \times 0.445)\end{array}$ & $\begin{array}{l}1: 1190 \text { (spectinomycin being } \\
\text { the more limiting active) }\end{array}$ \\
\hline G & Tilmicosin as tilmicosin phosphate & $250 \mathrm{mg}$ tilmicosin/ml & $566^{\mathrm{a}} \mathrm{mg}$ tilmicosin/ml & $\begin{array}{l}0.2 \mathrm{mg} / \mathrm{ml} \\
(=0.8 \mathrm{ml} \text { product } /)\end{array}$ & $1: 2830$ \\
\hline H & Neomycin as neomycin sulphate & $600 \mathrm{~g}$ neomycin $/ \mathrm{kg}$ & $50^{\mathrm{a}} \mathrm{mg}$ neomycin sulphate/ml & $\begin{array}{l}0.22 \mathrm{mg} / \mathrm{ml} \\
(=0.37 \mathrm{mg} \mathrm{product} / \mathrm{ml} \times 0.6)\end{array}$ & $1: 227$ \\
\hline | & Tylosin as tylosin tartrate & $800 \mathrm{~g}$ tylosin $/ \mathrm{kg}$ & $50^{\mathrm{a}} \mathrm{mg}$ tylosin tartrate $/ \mathrm{ml}$ & $\begin{array}{l}0.2 \mathrm{mg} / \mathrm{ml} \\
(=0.25 \mathrm{mg} \mathrm{product} / \mathrm{ml} \times 0.8)\end{array}$ & $1: 250$ \\
\hline
\end{tabular}

a Source: TOKU-E (2016).

${ }^{\mathrm{b}}$ Source: Yalkowsky et al. (2010). 
administered to pigs. It highlights the challenges of using high concentration stock solutions in proportional dosing pumps of water-soluble antimicrobial products containing amoxicillin, trimethoprim-sulphadiazine and chlortetracycline. Even a stock solution with a concentration of $3.5 \mathrm{mg}$ active amoxicillin/ml, intended for injecting into the drinking water supply line at a ratio of $1: 33$ by volume, exceeds the solubility of amoxicillin in water.

Drinking water sources on Australian pig farms may be a municipal water supply, surface water from a nearby river, lake or farm dam or underground water extracted from a bore. Bore water is the most commonly used water source, with surface water the next most common. The quality of the water from both these sources can be highly variable, as most bores in agricultural regions of Australia are relatively shallow, extracting water from upper aquifers (Edwards, 2018; Victorian Government Department of Environment, Land, Water and Planning, 2019).

The solubility of the active antimicrobial may be influenced by the water's $\mathrm{pH}$, concentration of salts and metal ions, and the temperature of the water with which it is mixed (Yalkowsky et al., 2010). However, water-soluble antimicrobial products may contain non-active constituents intended to improve solubilisation of the active constituent (Kalepu and Nekkanti, 2015). For example, the solubility of amoxicillin is affected mainly by the $\mathrm{pH}$ of the water. Over an intermediate $\mathrm{pH}$ range (approximately 3.5 to 6.5 ), at which the amoxicillin molecule has components with positive and negative charges and an overall charge of zero (i.e. its zwitterionic form), solubility is at its minimum. At very low and very high $\mathrm{pH}$ levels, where cations or anions predominate, solubility is substantially increased. The temperature and the salt concentration of the aqueous solution have a lesser effect on the solubility of amoxicillin (Crea et al., 2012; Felix et al., 2016).

\section{Antimicrobial product stability and homogeneity}

The stability of an antimicrobial in solution may be affected over time by many external factors, including water $\mathrm{pH}$, water hardness, water pipe materials, chlorine, metal ions, $\mathrm{pH}$ modifiers, other antimicrobials and stability enhancers (Dorr et al., 2009; Jerzsele and Nagy, 2009; Acero et al., 2010). Amoxicillin degrades much more rapidly over a 24-h period when in contact with metal (galvanised steel) compared to plastic. Amoxicillin degrades more rapidly in water with a neutral to high $\mathrm{pH}$ than in water with a low $\mathrm{pH}$. Jerzsele and Nagy (2009) found that after $24 \mathrm{~h}$ mixed in aqueous solutions with a pH of 10, 7 and 3, the proportions of initial amoxicillin concentration retained were $68.2 \%$, $72.4 \%$ and $79.6 \%$ respectively. Sodium carbonate (soda ash), which is commonly added to amoxicillin products in stock solutions to enhance solubility, thus may enhance degradation. To a lesser extent, amoxicillin degrades more rapidly in water that is moderately hard to hard (>100 mg equivalent $\mathrm{CaCO}_{3} /$ /) (Jerzsele and Nagy, 2009).

Chlorine reacts with several classes of antimicrobials, including amoxicillin, tetracyclines, trimethoprim and fluoroquinolones (Postigo and Richardson 2014). Amoxicillin is very sensitive to chlorine at concentrations commonly used to disinfect drinking water. Acero et al. (2010) found that amoxicillin was very rapidly removed from water with chlorine concentrations between 0.2 and $1 \mathrm{mg} / \mathrm{l}$, as typically used in full-scale drinking water treatments by chlorine. Amoxicillin is not very reactive with other antimicrobials, with a precipitate forming only when it is mixed with chlortetracycline. Interactions between other commonly used antimicrobials may occur, resulting in precipitates (Dorr et al., 2009).

Products containing the same active constituent do not necessarily retain $>95 \%$ of their initial concentration at $24 \mathrm{~h}$ after mixing, as shown in a study by Boeren et al. (2006) that compared eight water-soluble amoxicillin products. Two of the eight unnamed products assessed only retained $52.3 \%$ and $55 \%$ of their initial amoxicillin concentration of $4.8 \mathrm{mg} / \mathrm{ml}$ at $24 \mathrm{~h}$ after mixing. This suggests that only high quality antimicrobial products can be assumed to yield stable stock solutions, and that fresh batches of stock solutions should be prepared daily.

\section{Passage of antimicrobial product through drinking water distribution system}

There is a lag between commencement of a water medication dosing event and delivery of medicated water to pigs in a pen within a shed. Consistent with the nature of steady-state fluid flow through pipelines, the lag time is a function of: (1) the distance between the header tank or dosing pump and the pen, and (2) the velocity at which water flows through the drinking water distribution system to the drinking appliances in the pen. The concentration of antimicrobial in water at the drinking appliance over time is then a function of the concentration of antimicrobial in drinking water being discharged from the header tank or in the water supply line just downstream of the dosing pump over time and the velocity at which water flows through the distribution system (Crane Co. Staff, 2011). When a header tank is being used, the inlet valve may be deliberately left open so the tank continuously refills with unmedicated water, and top-up boluses of medication added. If so, then the concentration of antimicrobial in water flowing from the tank along the water line to pigs is likely to fluctuate considerably over time.

To deliver water to pigs through a farm's piped drinking water distribution system, pressure is required. This is provided either by gravity (from an elevated water source or storage facility) or by one or more pumps. The system must provide a minimum pressure during periods of peak demand and acceptable working pressures during average demand periods, so that water flow rates from drinking appliances in pens at the end of the water line are acceptable at all times. Hourly demand may increase if water is being used for other purposes, such as pressure-washing concrete pens in a building or spray cooling in hot weather (Crane Co. Staff, 2011).

Frictional pressure losses occur along every section of the pipe system. They are largely a function of the lengths, diameters and internal surface smoothness of pipes, the number and types of fittings installed along the pipeline and the velocity of the water flow. Excessive numbers of bends 

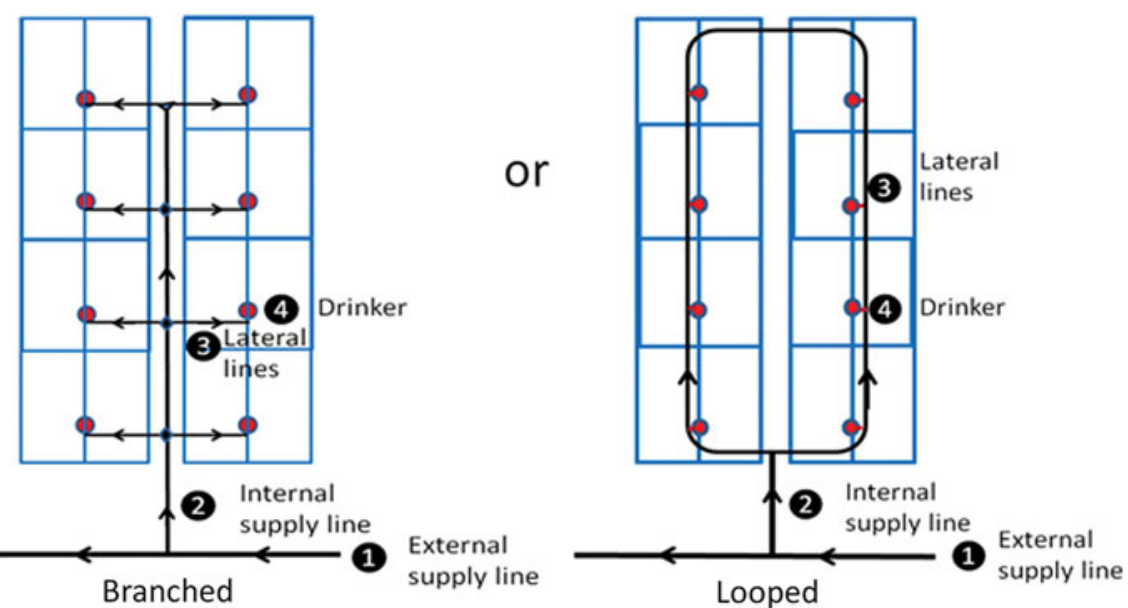

Figure 2 (Colour online) Two alternative configurations of a drinking water distribution system for a conventional, concrete-floored building housing weaner pigs (Adapted from AHDB Pork, 2018).

and changes in the diameters of pipes along the water line (constrictions or expansions) result in pressure losses due to deceleration and flow separation downstream. It is possible that these disturbances in flow may be advantageous during medication dosing events if they provide in-line mixing and reduce sedimentation of insoluble particles. Changes in pressure (head loss) along a water pipeline due to friction can be calculated using the Darcy-Weisbach equation (Crane Co. Staff, 2011).

Water supply lines supplying buildings and pens within buildings may be branched or looped (Figure 2). In a branched system, water velocities and pressure losses are greater than in a looped system, and capacity is reduced, especially during periods of high demand. There may be many dead ends where water is stagnant and sediments may accumulate. A looped system requires greater length of piping and more valves than a branched system and is therefore generally more costly than a branched system to construct, but has several advantages: greater reliability, ease of repair and maintenance, and the ability to provide water flow with a pump of smaller capacity (Watts et al., 2016). A farm's drinking water distribution system may fail to provide every pig in each pen, in each building, with unrestricted access to drinking water throughout the day if it has been poorly designed or modified over time without due regard for the key principles of fluid mechanics, or if sections of pipe have become partially occluded by mineral build-up or biofilms.

\section{Variability in medicated water consumption patterns of pigs over time}

\section{Water usage patterns and drinking behaviour}

During a water medication dosing event, the patterns of consumption of medicated water by pigs in each pen over time are subject to pigs' diurnal activity rhythm, with most feeding and drinking activity occurring during daylight hours. This diurnal water consumption usage pattern is maintained by pigs even when they are housed in sheds with continuous lighting (Meiszberg et al., 2009). Drinking occurs in frequent, short bouts. Water consumption and drinking patterns are driven by satiety and also influenced by factors including stress, boredom, hunger, environmental temperature, disease, feed type and constituents and water flow rates. Like many animals, pigs are prandial drinkers, with $75 \%$ to $85 \%$ of their drinking events being related to meals.

Using the data reported by Li et al. (2005) in Tables 1 and 3 of their paper from two experiments exploring water intake and wastage with several combinations of water flow rates and drinker heights, we calculated mean daily voluntary water consumptions of growing pigs of between 60 and $117 \mathrm{ml} / \mathrm{kg} \mathrm{BW}$. Water consumption over each 24-h period is characterised by one or two distinct peaks, with several studies observing two distinct peaks - one after sunrise and another in the mid-late afternoon (Madsen and Kristensen, 2005; Rousseliere et al., 2016). As pigs grow, and their daily water usage increases with BW, the amplitude of each peak in usage becomes greater. The timing, shape and amplitude of the peaks in water usage may be influenced by environmental conditions within the building, particularly ambient temperature and humidity. Diurnal drinking patterns have been found to vary markedly between winter and summer, presumably as an adaptation to heat stress (Brumm, 2006).

Recent studies that have used automated video or radiofrequency identification (RFID)-based systems to measure water usage/consumption patterns of individual animals have found large variations between animals and within animals over time. Andersen et al. (2014) used RFID ear tags and readers over drinking appliances coupled with electronic water flow meters to study water usage patterns and drinking behaviour of individual pigs ( 8 to 9 weeks old) in 8-h periods over 4 days when housed in pen groups of 3 and 10 animals. Mean daily water usages were 4767 and $5212 \mathrm{ml}$ for pigs penned in groups of 3 and 10 respectively, with a large SD of 753. Water usages of individual pigs within each 8-h period were also highly variable. Soraci et al. (2014) measured the daily water usage of $30 \mathrm{~kg}$ pigs, housed in pen groups of 18 , using a video system and water flow meters. Mean water usage was 3.7 I/day (SD: 0.3 l/day). Rousseliere 
et al. (2016) used an RFID system and water flow meters to measure daily water usage of individual pigs (7 to 10 weeks old) penned in groups of 19. Mean water usage was $107 \mathrm{ml} / \mathrm{kg} \mathrm{BW}$. The mean number of visits by pigs to drinking appliances each day was 27.2 (SD: 12.3), and mean water consumed by each pig on each visit to the drinker was $104 \mathrm{ml}$ (SD: $133 \mathrm{ml}$ ). Large between and within-animal variations in water drinking behaviour were observed within each pen group over a 22-day period.

Pigs are very social animals. Social hierarchies may have a substantial impact on between-animal variability in the water consumption and drinking patterns (Soraci et al., 2014). When a small pen group of pigs (e.g. 20 pigs) is formed, they quickly establish their social ranks within the group, and each pig's social rank within the group then remains relatively stable. Day to day, intermediate and lowly ranked pigs in the group may be subject to acts of aggression by higher ranked pigs attempting to control and dominate limited resources in the pen (i.e. feed and water). If so, this could contribute substantially to between-animal variability in daily consumption of feed and water, and to feeding and drinking patterns within a pen, and ultimately systemic exposure to an antimicrobial during medication.

The study by Soraci et al. (2014) found that in a small pen group, social rank in the group explained up to around onethird of the between-animal variation in systemic exposure to an antimicrobial. It appears that social facilitation (the tendency for animals to synchronise their behaviour) influences drinking behaviour in pigs to some extent (Turner et al., 2000). When pigs are housed in a large pen group (greater than about 100 pigs), they do not attempt to control resources such as feeders and drinking appliances, opting instead to adopt a more tolerant and less aggressive social strategy (Samarakone and Gonyou, 2009). This may result in less between-animal variability in daily water consumption and drinking patterns.

\section{Other known factors that may influence water consumption and drinking patterns \\ Disease. Most studies indicate that pigs suffering from diar- rhoea caused by Salmonella spp. or Escherichia coli, or res- piratory disease caused by Actinobacillus pleuropneumoniae, consume less water per day, have altered drinking patterns and commonly have reduced feed consumption (Pijpers et al., 1991; Krsnik et al., 1999; Ahmed et al., 2015).}

Feed type and constituents. While diets with excessive protein levels may result in increased water consumption, generally dietary factors appear to have minimal impact on water consumption (Shaw et al., 2006).

Water flow rate. Provided the number of drinking appliances in a pen is appropriate for the pen group size, older pigs can readily increase their drinking time to compensate for water flow rates from drinking appliances that are lower than those appropriate for their BW. However, younger pigs may not be able to adapt sufficiently, resulting in lower daily water use, feed consumption and growth rates (Neinaber and Hahn, 1984; Barber et al., 1989).
Daily water wastage by pigs may range from $9 \%$ to $60 \%$ of total water usage, depending on many factors, including water flow rates, drinker design and position, room temperature, levels of competition between pigs, diet and water quality (Li et al., 2005; Meiszberg et al., 2009; Andersen et al., 2014, Wang et al., 2017). Unfortunately, many published studies investigating the drinking behaviour of pigs have only measured the total water usage/disappearance, without measuring the volume spilled by pigs, and the terms 'water usage/disappearance' and 'water consumption' have often been used interchangeably. Patterns of pigs' water consumption and wastage within each 24-h period under different herd management and environmental conditions have not been documented simultaneously.

\section{Variability in pharmacokinetics}

During and after a water medication dosing event, betweenanimal variability in the time course of plasma concentrations of an antimicrobial may be due to differences in one or more of the following processes: oral bioavailability, the rate of drug absorption, the apparent volume of distribution, clearance from the central compartment or plasma and distribution to peripheral compartments in the animal's body. Even small differences between pigs in these processes, especially oral bioavailability, may have substantial effects on the plasma antimicrobial concentration-time curve, regardless of variability in the dose applied and consumed by pigs over time.

\section{Oral bioavailability of different antimicrobials}

The oral bioavailability of different antimicrobials in the pig varies widely. While the oral bioavailability of sulphadiazine/ trimethoprim and of enrofloxacin is over $80 \%$, that of oxytetracycline and of chlortetracycline is very low, at less than $10 \%$. The oral bioavailability of amoxicillin is generally low, with reported values varying widely from $11 \%$ to 48\% (Agersø and Friis, 1998b; Godoy et al., 2011). The low bioavailability of amoxicillin after oral administration could be explained by a pre-systemic loss, probably in the intestine.

Oral bioavailability may be influenced by the presence of food in the gastrointestinal tract at the time of antimicrobial administration. Food-related effects on bioavailability have been observed in pigs for lincomycin, spiramycin, enrofloxacin, tetracycline and chlortetracycline, but not for amoxicillin and oxytetracycline (Nielsen and Gyrd-Hansen, 1996; Agersø and Friis, 1998b). Very little is known about between-animal variability in oral bioavailability and other PK parameters for specific antimicrobials. Whether an antimicrobial's oral bioavailability remains constant within a given pig over time, and is similar when the antimicrobial is administered as one or more boluses $v$. through drinking water provided ad libitum, is also not known. 
Table 2 Effects of different antimicrobial classes used in pigs

\begin{tabular}{|c|c|c|}
\hline Inhibitory action & Antibiotic classes & $\begin{array}{c}\text { Pharmacokinetic/ } \\
\text { pharmacodynamic index }\end{array}$ \\
\hline Time-dependent & $\begin{array}{l}\beta \text {-lactams } \\
\quad \text { (for efficacy) } \\
\text { Older macrolides } \\
\text { Lincosamides } \\
\text { Sulphonamides }\end{array}$ & Time $_{24 \mathrm{~h}}>\mathrm{MIC}^{*}$ \\
\hline Co-dependent & $\begin{array}{l}\text { Tetracyclines } \\
\beta \text {-lactams } \\
\text { (for resistance) } \\
\text { Fluoroquinolones } \\
\text { ( } v \text {. anaerobes) } \\
\text { New macrolides } \\
\text { (tulathromycin) }\end{array}$ & $\mathrm{AUC}_{24 \mathrm{~h}} \S / \mathrm{MIC}$ \\
\hline $\begin{array}{c}\text { Concentration- } \\
\text { dependent }\end{array}$ & $\begin{array}{l}\text { Aminoglycosides } \\
\text { Fluoroquinolones } \\
\text { Metronidazole } \\
\text { ( } v \text {. anaerobes) } \\
\text { Polymixins }\end{array}$ & $C_{\max } / \mathrm{MIC} \ddagger$ \\
\hline
\end{tabular}

Source: Adapted from Turnidge and Paterson (2007), Lees et al., (2015).

${ }^{*} \mathrm{MIC}=$ minimum inhibitory concentration of target pathogen.

$\S \mathrm{AUC}_{24} \mathrm{~h}=$ area under plasma antimicrobial concentration-time curve over $24 \mathrm{~h}$ following administration.

$\ddagger C_{\text {max }} / \mathrm{MIC}=$ maximum plasma concentration divided by MIC.

\section{Inhibitory action of different antimicrobials}

The optimal concentration and duration required for inhibiting a targeted bacterial pathogen vary with the different modes of action of antimicrobials. While some classes of antimicrobial have time-dependent effects, others have concentration-dependent effects, and some are dependent on both time and concentration. These different effects determine the PK/pharmacodynamic (PD) index that best predicts efficacy (Lees et al., 2015; Hardefeldt et al., 2019) (Table 2 and Figure 3).

For a $\beta$-lactam such as amoxicillin, for which efficacy is time-dependent, the targeted minimum inhibitory concentration (MIC) should be achieved for $\geq 40 \%$ to $50 \%$ of a $24-h$ period (i.e. 9.6 to $12 \mathrm{~h}$ ) to achieve a bactericidal effect (Rey et al., 2014). A study on another $\beta$-lactam antibiotic, cefotaxime, in mice showed that it had a bacteriostatic effect on Klebsiella pneumoniae when plasma levels were above the MIC for $30 \%$ to $40 \%$ of the dosing interval, but that plasma concentrations needed to be maintained above MIC for $60 \%$ to $70 \%$ of the dosing period to achieve maximal inhibition (Craig, 1998).

\section{Other factors that may alter pharmacokinetics in pigs}

Infectious diseases. Pigs infected with Salmonella typhimurium were found to have $54 \%$ greater systemic exposure to amoxicillin after intramuscular administration than healthy pigs, with faster absorption and a much longer terminal half-life (Agersø et al., 2000). Amoxicillin has been

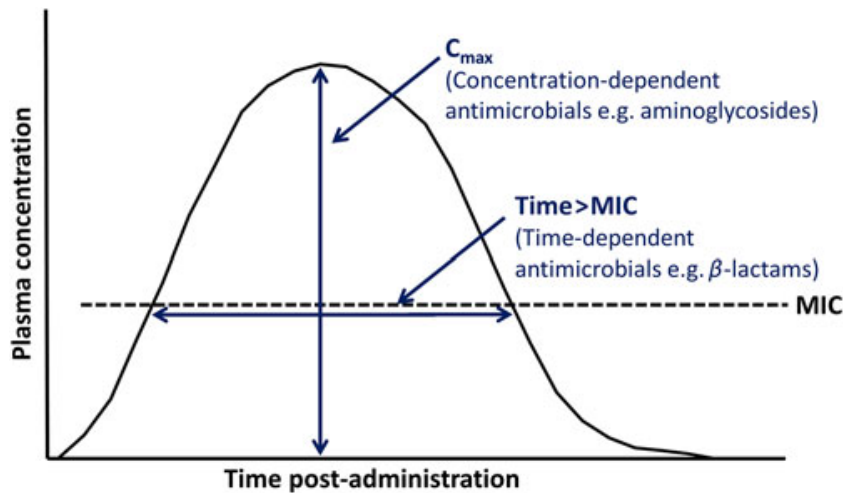

Figure 3 (Colour online) Principal pharmacokinetic-pharmacodynamic (PK-PD) characteristics of antimicrobial drugs in animals (Adapted from Hardefeldt et al., 2019). $C_{\max }=$ maximum plasma concentration, $M I C=$ minimum inhibitory concentration of target pathogen .

found to have significantly greater oral bioavailability $(44.7 \%$ v. $14.1 \%)$ in pigs with respiratory disease (Godoy et al., 2011). However, in pigs with E. coli-induced diarrhoea, the area under the plasma antimicrobial concentration-time curve (AUC) of amoxicillin was decreased by more than $50 \%$ on the first day after dosing in water for $4 \mathrm{~h}$, leading the authors to suggest that a higher loading dose may be appropriate (Jensen et al., 2006).

Aging. The impact of animal aging on the PKs of antimicrobials in pigs is unknown. This possibly reflects the complexity and diversity of animal aging across species and production systems. However, in rats an age-related improvement in the permeability of intestinal mucosa to one type of cephalosporin antimicrobial, cefazolin, was reported but not to another, cephradine (Morita et al., 1992). Changes in the PKs of antimicrobials and other types of drugs in elderly patients have been well described in the human pharmacology literature. For example, absorption, volume of distribution and clearance of amoxicillin may be reduced. Inter-patient variability in PK parameters is also greater in older patients than younger ones (Benson, 2017).

\section{Successful water medication of pigs at the group level}

Successful water medication of a group of pigs may be defined not only as an absence of clinical signs in pigs and achievement of maximum growth rates, but also as elimination (or at least a dramatic reduction in numbers) of the pathogen, and prevention (or at least minimisation) of the selection and propagation of resistant pathogens (Toutain and Lees, 2006). Success will depend on the plasma concentration of the antimicrobial and the length of time for which the target concentration is sustained.

When administering a dose of an antimicrobial to a group of pigs, a wide distribution of systemic exposures to the antimicrobial is observed due to the three sources of variability in exposure described in this review. When water medicating a group of 
pigs, the key question should therefore be: 'What is the probability that the majority of pigs in the group will attain the systemic exposure to the antimicrobial required to eliminate the target pathogen when using this administration regimen?'

The success of an administration regimen at a population level must therefore be expressed as the proportion of animals in the group that attain a defined target value for the PK/PD index that best predicts maximum efficacy for the antimicrobial based on its inhibitory action. This is denoted as the 'probability of target attainment' (PTA). An ideal value for this probability is situation-specific. However, a PTA of 0.9 is commonly chosen. If so, an administration regimen is considered sub-optimal unless at least $90 \%$ of the animals in a group attain a target value for the PK/PD index. For example, $50 \%$ of Time $24 \mathrm{~h}>$ MIC for amoxicillin. The clinical merit of a PTA of 0.9 is yet to be validated in clinical trials (Turnidge and Paterson, 2007; Rey et al., 2014).

The time at which a water medication dosing event is commenced and how quickly the quantity of antimicrobial is ingested by the pigs are critical. If dosing is commenced during a period of low water consumption by pigs, and the total dose of antimicrobial is consumed by pigs over an extended period, for example 12 to $24 \mathrm{~h}$, then the plasma concentration of the antimicrobial in pigs would be expected to rise slowly and the PK/PD index attained may not be high. Conversely, if dosing is commenced during a period when pigs' water consumption is moderate to high, and the total dose of antimicrobial is ingested by pigs over a shorter period, for example $8 \mathrm{~h}$, then the plasma concentration of the antimicrobial should rise more rapidly, leading to a higher PK/PD index being achieved. This could assist in achieving clinical efficacy and minimising development of antimicrobial resistance, as it aligns with the 'mutant selection window' (MSW) concept.

The MSW concept states that to minimise development of antimicrobial resistance it is best to administer a high dose of antibiotic over a short time period, to minimise the length of time in which the plasma concentration of the antimicrobial lies between the MIC and the higher 'mutant preventive concentration' (Lees et al., 2015). Violation of the MSW concept is more likely when water medication dosing events are not timed with periods of high water consumption, the dosing event is conducted over an extended period of time and/or a lower dose of antimicrobial per kilogram BW per day is being administered for metaphylaxis (rather than a higher dose for treatment of clinical disease).

\section{Conclusions}

Substantial between-animal variability in the systemic exposure of pigs to antimicrobials (i.e. the antimicrobial concentration in plasma over time) can occur during administration in drinking water, resulting in many pigs in a group being under-dosed or over-dosed. Sources of this variability are:
1. Variability in dose applied; that is, the concentration of the active antimicrobial in water available to pigs at drinking appliances in each pen over time,

2. Variability in dose consumed; that is, patterns of consumption of medicated water by pigs in each pen over time, and

3. Variability in PKs; that is, oral bioavailability, volume of distribution and clearance between pigs and within pigs over time.

Standard antimicrobial administration regimens for water medication on farms do not account for these sources of between-animal variability. They are based on the assumption that all animals will consume the same dose and will experience the same level of systemic exposure to the antimicrobial over time. If these sources of between-animal variability are better understood, antimicrobial administration regimens may be optimised for each farm situation to account for factors influencing the range of exposures of pigs in a group to the antimicrobial. Under-dosing and over-dosing may thereby be reduced.

More information is required before it would be possible to quantify the three sources of between-animal variability in systemic exposure to an antimicrobial administered through drinking water and determine their relative contributions to total between-animal variability. This would be very useful for determining where to focus efforts to reduce betweenanimal variability in systemic exposure to an antimicrobial on each farm and thus optimise the administration regimen.

\section{Acknowledgements}

The authors wish to thank the Australian pig producers and veterinarians for their support for research into water medication of growing pigs.

This work was supported by a National Health and Medical Research Council Centre for Research Excellence grant for the National Centre for Antimicrobial Stewardship. (1) S. B. Little 0000-0002-3715-3225

\section{Declaration of interest}

The authors have no conflicts of interest to disclose.

\section{Ethics statement}

Not required for this review.

\section{Software and data repository resources}

No new software or database was generated as part of the outcomes of this literature review.

\section{References}

Acero JL, Benitez FJ, Real FJ and Roldan G 2010. Kinetics of aqueous chlorination of some pharmaceuticals and their elimination from water matrices. Water Research 44, 4158-4170.

Agersø $\mathrm{H}$ and Friis C 1998a. Penetration of amoxycillin into the respiratory tract tissues and secretions in pigs. Research in Veterinary Science 64, 245-250.

Agersø $\mathrm{H}$ and Friis C 1998b. Bioavailability of amoxycillin in pigs. Journal of Veterinary Pharmacology and Therapeutics 21, 41-46. 
Agersø H, Friis C and Nielsen JP 2000. Pharmacokinetics and tissue distribution of amoxicillin in healthy and Salmonella Typhimurium-inoculated pigs. American Journal of Veterinary Research 61, 992-996.

AHDB Pork 2018. Designing a water supply system for livestock. Retrieved on 25 April 2019 from http://pork.ahdb.org.uk/media/275924/designingawatersupply system_180823_web.pdf

Ahmed ST, Mun H-S, Yoe H and Yang CJ 2015. Monitoring of behavior using a video-recording system for recognition of Salmonella infection in experimentally infected growing pigs. Animal 9, 115-121.

Andersen HML, Dybkjær L, Herskin MS. 2014. Growing pigs' drinking behaviour: number of visits, duration, water intake and diurnal variation. Animal 8 1881-1888.

Anfossi P, Zaghini A, Grassigli G, Menotta S and Fedrizzi G 2002. Relative oral bioavailability of microgranulated amoxicillin in pigs. Journal of Veterinary Pharmacology and Therapeutics 25, 329-334.

Barber J, Brooks PH and Carpenter JL 1989. The effects of water delivery rate on the voluntary food intake, water use and performance of early-weaned pigs from 3 to 6 weeks of age. British Society of Animal Production Occasional Publication 13, 103-104.

Benson JM 2017. Antimicrobial pharmacokinetics and pharmacodynamics in older adults. Infectious Disease Clinics of North America 31, 609-617.

Boeren M, Michiels D, Verhoeve P, Van Aken K and de Keijser H 2006 Amoxicillin stability and solubility. Paper presented at EPC 2006 - 12th European Poultry Conference, 10-14 September, 2006, Verona, Italy. pp325.

Bon C, Toutain P-L, Concordet D, Gehring R, Martin-Jimenez T, Smith J, Pelligand L, Martinez M, Whittem T, Riviere JE and Mochel JP 2018. Mathematical modelling and simulation in animal health. Part III: using nonlinear mixed-effects to characterize and quantify variability in drug pharmacokinetics. Journal of Veterinary Pharmacology and Therapeutics 41, 171-183.

Brumm M. 2006. Patterns of drinking water use in pork production facilities. Nebraska Swine Report. University of Nebraska-Lincoln. Retrieved on 25 April 2019 from https://digitalcommons.unl.edu/coopext_swine/221/

Craig WA 1998. Pharmacokinetic/pharmacodynamic parameters: rationale for antibacterial dosing of mice and men. Clinical Infectious Diseases 26, $1-12$.

Crane Co.Staff 2011. Flow of fluids through valves, fittings, and pipe. Issue 410 of Technical paper. Crane Co., Stamford, Conn., USA.

Crea F, Cucinotta D, De Stefano C, Milea D, Sammartano S and Vianelli G 2012. Modelling solubility, acid-base properties and activity coefficients of amoxicillin ampicillin and (+)6-aminopenicillanic acid, in $\mathrm{NaCl}(\mathrm{aq})$ at different ionic strengths and temperatures. European Journal of Pharmaceutical Sciences 47, 661-677.

del Castillo JRE, Laroute V, Pommier P, Zeémirline C, Keiïta A, Concordet D, Toutain P-L 2006. Interindividual variability in plasma concentrations after systemic exposure of swine to dietary doxycycline supplied with and without paracetamol: a population pharmacokinetic approach. Journal of Animal Science 84, 3155-3166.

Dorr PM, Madson D, Wayne S, Scheidt AB and Almond GW 2009. Impact of pH modifiers and drug exposure on the solubility of pharmaceutical products com monly administered through water delivery systems. Journal of Swine Health and Production 17, 217-222.

Edwards L 2018. Drinking water quality and its impact on the health and performance of pigs. Final Report prepared for the Co-operative Research Centre for High Integrity Australian Pork. PorkCRC, Willaston, South Australia Australia. Retrieved on 25 April 2019 from http://porkcrc.com.au/wp-content/uploads/ 2018/08/2A-118-Drinking-Water-Quality-Final-Report.pdf

Felix IMB, Moreira LC, Chiavone-Filho 0 and Mattedi S 2016. Solubility measurements of amoxicillin in mixtures of water and ethanol from 283.15 to $298.15 \mathrm{~K}$. Fluid Phase Equilibria 422, 78-86.

Godoy C, Castells G, Marti G, Capece BPS, Perez F, Colom H and Cristofol C 2011. Influence of a pig respiratory disease on the pharmacokinetic behaviour of amoxicillin after oral ad libitum administration in medicated feed. Journal of Veterinary Pharmacology and Therapeutics 34, 265-276.

Hardefeldt LY, Crabb HK, Bailey KE, Gilkerson JR, Billman-Jacobe $\mathrm{H}$ and Browning GF 2019. Antimicrobial dosing for common equine drugs: a content review and practical advice for veterinarians in Australia. Australian Veterinary Journal 97, 103-107.
Jensen GM, Lykkesfeldt J, Frydendahl K, Møller K and Svendsen 02006. Pharmacokinetics of amoxicillin administered in drinking water to recently weaned 3- to 4-week-old pigs with diarrhea experimentally induced by Escherichia coli 0149:F4. American Journal of Veterinary Research 67, 648-653.

Jerzsele J and Nagy $G$ 2009. The stability of amoxicillin trihydrate and potassium clavulanate combination in aqueous solutions. Acta Veterinaria Hungarica 57, 485-493.

Kalepu $S$ and Nekkanti $V$ 2015. Insoluble drug delivery strategies: review of recent advances and business prospects. Acta Pharmaceutica Sinica B 5, $442-453$

Krsnik B, Yammine R, Pavičić Ž, Balenović T, Njari B, Vrbanac I and Valpotić 1999. Experimental model of enterotoxigenic Escherichia coli infection in pigs: potential for an early recognition of colibacillosis by monitoring of behavior. Comparative Immunology, Microbiology and Infectious Diseases 22, 261-273. Lees P, Pelligand L, Ferran A, Bousquet-Melou A and Toutain P-L 2015. Application of pharmacological principles to dosage design of antimicrobial drugs. Pharmacology Matters, 8, 22-24.

Li YZ, Cheénard L, Lemay SP and Gonyou HW 2005. Water intake and wastage at nipple drinkers by growing-finishing pigs. Journal of Animal Science 83, 1413-1422.

Lindquist D, Wu H, Mason S, Yeatts J, Brooks J, Barlow B, Schill K and Baynes R 2014. Tetracycline residues in porcine stomach after administration via drinking water on a swine farm. Journal of Food Protection 77, 122-126.

Madsen TN and Kristensen AR 2005. A model for monitoring the condition of young pigs by their drinking behaviour. Computers and Electronics in Agriculture $48,138-154$

Mason SE, Baynes RE, Almond GW, Riviere JE and Scheidt AB 2009. Pharmacology of tetracycline water medication in swine. Journal of Animal Science 87, 3179-3186.

Meiszberg AM, Johnson AK, Sadler L, Carroll JA, Dailey JW and Krebs N 2009 Drinking behavior in nursery pigs: determining the accuracy between an automatic water meter versus human observers. Journal of Animal Science 87, 4173-4180. Morita E, Mizuno N, Nishikata M and Takahashi K 1992. Effect of gastrointestinal maturation on absorption of $\beta$-lactam antibiotics. Journal of Pharmaceutical Sciences 81, 337-340.

Nielsen P and Gyrd-Hansen N 1996. Bioavailability of oxytetracycline, tetracycline and chlortetracycline after oral administration to fed and fasted pigs. Journal of Veterinary Pharmacology and Therapeutics 19, 305-311.

Neinaber JA and Hahn GL 1984. Effects of water flow restriction and environmental factors on performance of nursery-age pigs. Journal of Animal Science 59, 1423-1429.

Pijpers A, Schoevers EJ, van Gogh H, van Leengoed LAMG, Visser IJR, van Miert ASJPAM and Verheijden JHM 1991. The influence of disease on feed and water consumption and on pharmacokinetics of orally administered oxytetracycline in pigs. Journal of Animal Science 69, 2947-2954.

Postigo C and Richardson SD 2014. Transformation of pharmaceuticals during oxidation/disinfection processes in drinking water treatment. Journal of Hazardous Materials, 279, 461-475.

Prats C, El Korchi G, Giralt M, Cristofol C, Pena J, Zorrilla I, Saborit J and Perez B 2005. PK and PK/PD of doxycycline in drinking water after therapeutic use in pigs. Journal of Veterinary Pharmacology and Therapeutics 28, 525-530.

Rey JF, Laffont CM, Croubels S, De Backer P, Zemirline C, Bousquet E, Guyonnet J, Ferran AA, Bousquet-Melou A and Toutain P-L 2014. Use of Monte Carlo simulation to determine pharmacodynamic cutoffs of amoxicillin to establish a breakpoint for antimicrobial susceptibility testing in pigs. American Journal of Veterinary Research 75, 124-131.

Reyns T, De Boever S, Baert K, Croubels S, Schauvliege S, Gasthuys F and De Backer P 2007. Disposition and oral bioavailability of amoxicillin and clavulanic acid in pigs. Journal of Veterinary Pharmacology and Therapeutics 30, 550-555.

Rousseliere Y, Hemonic A, Marcon M 2016. Individual monitoring of the drinking behavior of weaned piglets. Journées Recherche Porcine 48, 355-356.

Samarakone TS and Gonyou HW 2009. Domestic pigs alter their social strategy in response to social group size. Applied Animal Behaviour Science 121, 8-15.

Shaw MI, Beaulieu AD and Patience JF 2006. Effect of diet composition on water consumption in growing pigs. Journal of Animal Science 84, 3123-3132. 
Little, Crabb, Woodward, Browning and Billman-Jacobe

Soraci AL, Amanto F, Tapia MO, de la Torre E and Toutain P-L 2014. Exposure variability of fosfomycin administered to pigs in food or water: Impact of social rank. Research in Veterinary Science 96, 153-159.

TOKU-E 2016. Antibiotic solubility data table. Retrieved on 25 April 2019 from https://www.toku-e.com/Antibiotic-Solubility-Data-Table.aspx

Toutain P-L and Lees P 2006. The population PK/PD approach for a rational use of anti-infective drugs to minimize resistance. Journal of Veterinary Pharmacology and Therapeutics 29, 26-29.

Turner SP, Sinclair AG and Edwards SA 2000. The interaction of liveweight and the degree of competition on drinking behaviour in growing pigs at different group sizes. Applied Animal Behaviour Science 67, 321-334.

Turnidge JP and Paterson DL 2007. Setting and revising antibacterial susceptibility breakpoints. Clinical Microbiology Reviews 20, 391-408.
Victorian Government Department of Environment, Land, Water and Planning 2019. Groundwater sites. Retrieved on 25 April 2019 from http://data.water. vic.gov.au/static.htm

Wang M, Yi L, Liu J, Zhao W and Wu Z 2017. Water consumption and wastage of nursery pig with different drinkers at different water pressures in summer. Transactions of the Chinese Society of Agricultural Engineering 33, 161-166.

Watts PJ, Davis RJ, Keane OB, Luttrell MM, Tucker RW, Stafford R and Janke S 2016. Beef cattle feedlots: design and construction. Meat \& Livestock Australia, North Sydney, NSW, Australia.

Yalkowsky SH, He Y and Jain P 2010. Handbook of aqueous solubility data. 2nd edition. CRC Press, Taylor \& Francis Group, Boca Raton, FL, USA. 